\title{
A ação coletiva e a cooperaçáo no Sistema Único de Saúde
}

\section{I ${ }^{1}$ João Felipe Marques da Silva, ${ }^{2}$ Silvia Karla Azevedo Vieira Andrade, ${ }^{3}$ Brígida Gimenez Carvalho, ${ }^{4}$ Carolina Milena Domingos I}

Resumo: Embora o princípio de regionalização dos serviços de saúde conste em documentos oficiais e norteie a organização atual do Sistema Único de Saúde, esse processo depende em certa medida da ação coletiva e da cooperação entre os entes federados. Consideram-se a ação coletiva e a cooperação como elementos de políticas federativas e como comportamento social. Nesta perspectiva, buscou-se analisar como a ação coletiva e a cooperação são abordadas nos documentos oficiais de regulamentação e organização das políticas de saúde que tratam da regionalização. Trata-se de uma análise documental de 16 normas oficiais, publicadas entre 1988 e 2018, e discussão do tema, apoiado sobretudo nos referenciais de coletividade e institucionalidade política. Para a análise dos documentos oficiais, utilizou-se a técnica de análise do conteúdo. Os resultados apontam que a ação coletiva e a cooperação são abordadas em documentos oficiais, especialmente pelos vocábulos "solidariedade" e "cogestão", e que as políticas de regionalização possuem caráter altamente normativo. Sua implementação dependerá de mecanismos de coordenação, coerção e recompensa, além de aspectos relacionados à gestão dos serviços, como equilíbrio entre os interesses coletivos e individuais, e a construção de identidades sociais entre gestores com vistas à cogestão.

> Palavras-chave: planejamento regional de saúde; ação coletiva; cooperação; descentralização, políticas públicas.

\author{
1 Programa de Pós Graduação \\ em Saúde Coletiva, Universidade \\ Estadual de Londrina. Londrina- \\ PR, Brasil (jmfliper@hotmail.com). \\ ORCID: 0000-0001-7198-8528

\footnotetext{
2 Programa de Pós Graduação em Saúde Coletiva, Universidade Estadual de Londrina. Londrina-PR, Brasil (silviakarla77@gmail.com). ORCID: 0000-0003-4971-5587

${ }^{3}$ Programa de Pós Graduação em Saúde Coletiva, Universidade Estadual de Londrina. LondrinaPR, Brasil (brigidagimenez@ gmail.com).

ORCID: 0000-0003-3850-870X

${ }^{4}$ Programa de Pós Graduação em Saúde Coletiva, Universidade Estadual de Londrina. LondrinaPR, Brasil (carolinamdomingos@ gmail.com).

ORCID: 0000-0002-7725-1831
}

Recebido em: 21/03/2020 Aprovado em: 13/08/2020 Revisado em: 10/09/2020 


\section{Introdução}

Pautada na Constituição Federal de 1988 e em diversas outras normativas infraconstitucionais, a cooperação interfederativa enquanto elemento de organização política se apresenta como característica imprescindível ao desenvolvimento das políticas sociais no Brasil. $\mathrm{Na}$ saúde, por exemplo, mostra-se como componente central nos documentos oficiais do Sistema Único de Saúde (SUS), e embora faça parte do seu arcabouço normativo, sua concretizaçáo revela-se um processo difícil e de complexa institucionalização (MENICUCCI; MARQUES, 2016).

Inúmeros fatores podem ajudar a compreender por que a cooperação entre gestores não se apresenta efetiva na prática dos serviços de saúde. Aponta-se, entre eles, o enfoque dado na década de 1990 para as açôes de descentralização federativa em relação à organização de arranjos coletivos de prestação de serviços. A ênfase às açóes de descentralizaçáo incentivou o ente municipal a desenvolver articulaçóes próprias para a organização dos serviços de saúde de seu território. Esse processo, em menos de uma década, apresentou evidências do esgotamento potencial das iniciativas individuais dos municípios quanto à organização do sistema de saúde local, apontando a necessidade de implementar a ação coletiva como fator essencial para as relaçóes federativas (CARVALHO et al., 2019).

Na tentativa de superar esses obstáculos, o Ministério da Saúde, no início dos anos 2000, direcionou discussōes e publicações para fomentar o processo de regionalização. Compreende-se que a regionalização é dependente da ação coletiva ou da cooperação entre os entes federados, o que é condicionado por fatores diversos, visto que se refere a um processo político e administrativo que se traduz pela necessidade de organizar redes de atenção à saúde em diferentes territórios, otimizar e incorporar tecnologia, e qualificar a alocação de recursos humanos e materiais (VIANA; LIMA, 2011; LIMA, 2015).

Em tese, a ação coletiva regionalizada tende a alcançar melhores resultados e com menor custo aos serviços de saúde, ao permitir a otimização de recursos e sua utilização solidária entre municípios, além de ampliar o acesso e garantir melhor rentabilidade aqueles municípios com maior capacidade de atendimento (MENICUCCI; MARQUES, 2016). No entanto, sabe-se que o processo de ação coletiva em sistemas de saúde formados por princípios igualitários, descentralizados e regionalizados, como o SUS, é necessariamente lento e negociado, uma vez que 
envolve jogos de cooperação e negociação, acordos e vetos entre entes federados. Envolve também o entendimento entre autoridades políticas dotadas de vários tipos de legitimidade e que, por vezes, possuem projetos políticos distintos; além de ser favorecido e/ou potencializado por contextos histórico-estruturais e aspectos político-institucionais (VIANA; LIMA, 2011).

Considera-se, portanto, que a regionalização, sobretudo nas últimas duas décadas, norteia o processo de organização política do sistema de saúde brasileiro, e que a organização de serviços regionalizados pressupóe a formação de arranjos de cooperação e ação coletiva entre os entes federados. Desta forma, pretende-se com este manuscrito analisar como a ação coletiva e a cooperação são abordadas nos documentos oficiais de regulamentação e organização das políticas de saúde que tratam da regionalização no período de 30 anos de implantação do SUS no Brasil.

Parte-se do pressuposto que a açáo coletiva e a cooperação podem ser compreendidas por dois aspectos principais. O primeiro entendendo a cooperação e a ação coletiva enquanto elementos centrais em políticas públicas implementadas em contextos federativos do tipo cooperativo, como no caso brasileiro, especialmente no que se refere à relação entre entes federados; o segundo aspecto as considera resultados de um conjunto de comportamentos individuais que se manifestam socialmente, extrapolando assim a característica exclusivamente técnico-política desse conceito.

Quanto à compreensão da ação coletiva e da cooperação como comportamento social, a literatura apresenta enfoques antagônicos a seu respeito. $O$ primeiro admite que os indivíduos cooperem por interesses racionais para atender a seus próprios interesses (OLSON, 2015). Em contrapartida, outra parte da literatura apresenta que a ação coletiva e a cooperação também ocorrem em situações em que os atores envolvidos não se motivam apenas atraídos por vantagens ou benefícios individuais, mas também pela busca de bens imensuráveis, como a solidariedade e a identidade (MELLUCI, 1989). Além disso, cada ator político pode contribuir para o capital social, que é compreendido como um bem público que tende a ser cumulativo e autorreforçado, e que inclui normas de reciprocidade, redes de solidariedade e confiança entre as pessoas (PUTNAM, 1993).

Nessa perspectiva, a concretização da ação coletiva e da cooperação, enquanto elementos políticos, dependerá de diversos mecanismos, entre eles os regulatórios, que expressam recompensas e incentivos aos que cooperam, e coerçôes e puniçôes 
aos que desertam (SCOTT, 1995). Outrossim, sua materialização é expressamente dependente da trajetória e está relacionada ao desenvolvimento e aos resultados das políticas, caminhos, escolhas e consequências, percorridas anteriores à sua implementação (PIERSON, 2004).

\section{Metodologia}

Realizou-se análise documental das normas oficiais brasileiras relacionadas ao processo de regionalização dos serviços de saúde, publicadas entre o período de 1988 a 2018. Foram excluídos os documentos relativos a transferência de recursos e custeio de serviços específicos, e instrumentos secundários destinados ao detalhamento de portarias que envolvem o financiamento regional, bem como os que conferiam categorias de gestão aos entes envolvidos.

A busca das normativas foi realizada utilizando a palavra-chave "regionalização" no portal eletrônico SAÚDE LEGIS (http://portal2.saude.gov.br/saudelegis), na seção Pesquisa de Norma, acessado em dezembro de 2018. Foram levantados 50 documentos oficiais.

Para complementação da busca, também foram incluídas seis normas oficiais norteadoras do processo de regionalização, conforme a publicação "Ciclos de descentralização e regionalização das políticas de saúde” (VIANA; LIMA, 2011), e outras três normas por sua relevância com o tema. Estas últimas são as constituintes do arcabouço jurídico-normativo do sistema (CF 1988 e Lei no 8080/90), que destacam a regionalização como eixo estruturante do SUS, além da Lei Complementar $n^{\circ}$ 141/2012, que direciona despesas e gastos nos serviços de saúde, publicada após o Decreto $\mathrm{n}^{\circ} 7508 / 2011$, que enfatiza o processo de regionalização.

Assim, foram analisados 59 documentos. Destes, um apresentava-se duplicado, resultando em 58, e após a aplicação dos critérios de exclusão chegou-se a um total de 16 instrumentos jurídicos oficiais que abordam o tema em estudo (figura 1). 
Figura 1. Fases de seleção dos instrumentos oficiais da pesquisa, 2019

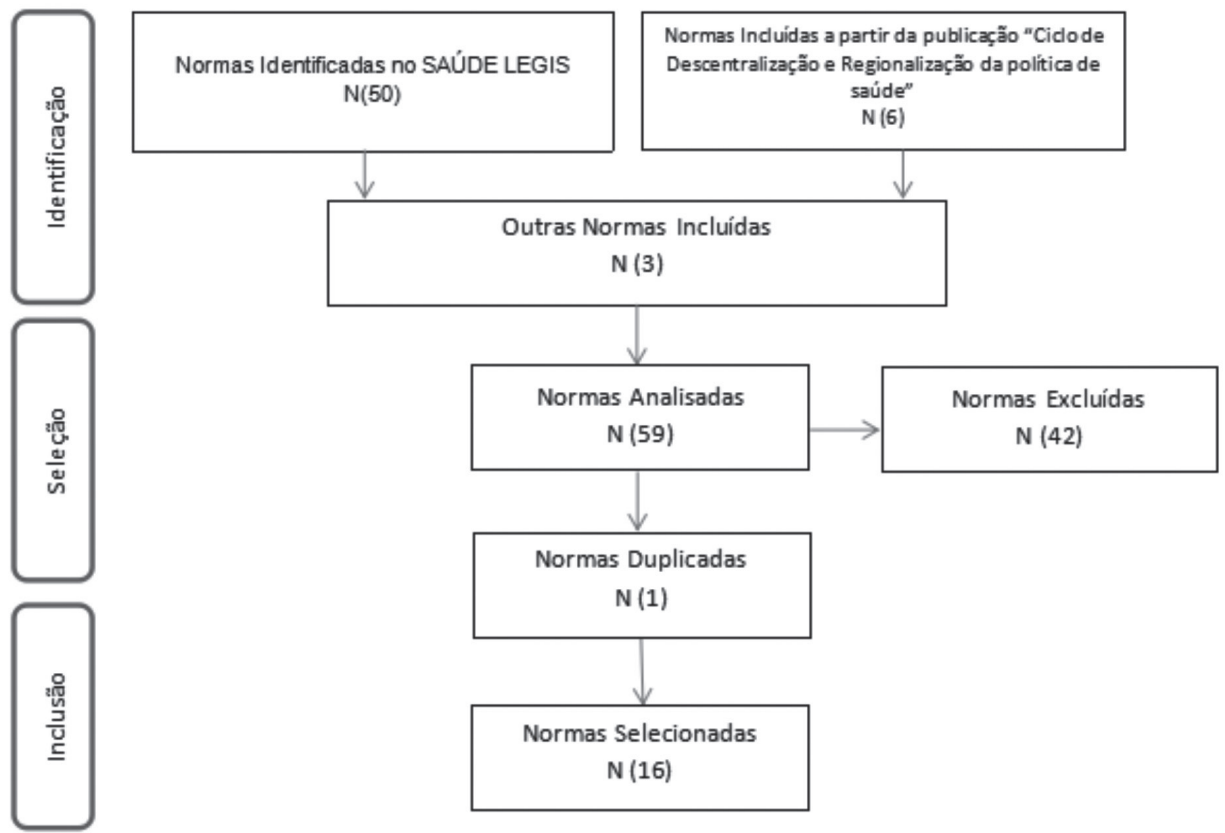

Fonte: os autores.

Adaptado de: PRISMA Group (2009).

No processo de análise dos documentos oficiais, procurou-se averiguar como as normas que abordam a regionalização tratam aspectos que envolvem a ação coletiva e cooperação entre os entes federados. Para tanto, utilizou-se a técnica de análise de conteúdo (MINAYO, 2010; BARDIN, 1977), por meio das seguintes etapas: a) leitura geral do material coletado; b) recortes do material em unidades de registro palavra, utilizando-se dos termos "regionalização", "ação coletiva" e "cooperação"; e c) compreensão dos recortes por inferência e interpretação. Após a seleção dos recortes, os resultados foram discutidos baseados no mapa conceitual proposto para análise da ação coletiva (figura 2).

Diante da multiplicidade e complexidade dos fatores envolvidos na efetivação da ação coletiva/cooperação entre gestores com vistas à regionalização no SUS, utilizouse a contribuição de diferentes abordagens teóricas que auxiliassem na compreensão e discussão do objeto de pesquisa, entendendo que sua concretização depende de aspectos individuais, regulatórios e institucionais. 
Nesta análise, a ação coletiva e a cooperação entre os entes federados no sistema de saúde encontram-se relacionados: à compreensão desta prática sob a ótica da coletividade (GOHN, 1977, 2000; MELUCCI, 1989; 2001; PUTNAM, 1993; OLSON, 2015); ao grau de sua institucionalização como política pública (SCOTT, 1995); e ainda, às influências sobre o sistema e seus atores institucionais, provocadas pelo caminho percorrido e pelas escolhas anteriores à sua implementação (PIERSON, 2004).

\section{Figura 2. Mapa conceitual de análise}

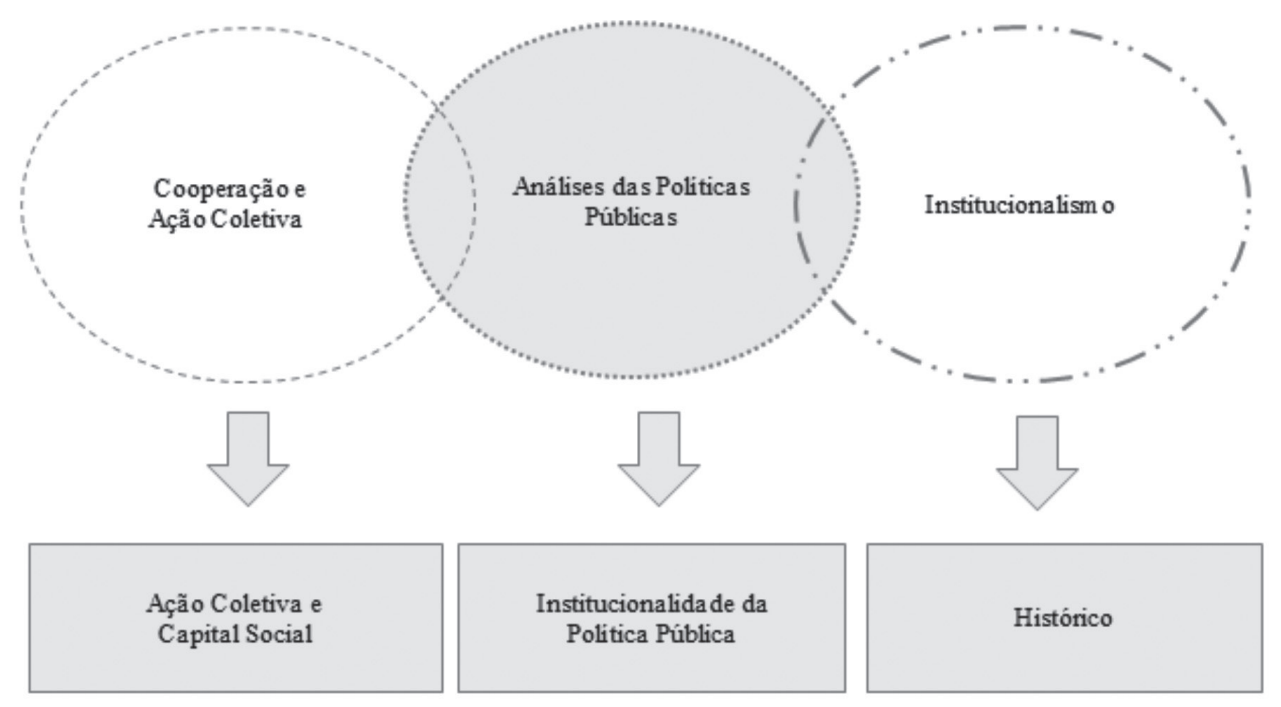

Fonte: os autores.

\section{Resultados evidenciados e discussão dos achados}

Para apresentação dos resultados, ilustrou-se o detalhamento dos instrumentos jurídicos utilizados apontando aspectos relacionados à ação coletiva e à cooperação nos documentos oficiais de regulamentação e organização das políticas de saúde, que tratam da regionalização no período de 30 anos de implantação do sistema de saúde no Brasil (quadro 1).

A análise desses instrumentos permitiu inferir determinados aspectos que não se restringem à condição de sentido dos termos "ação coletiva" e "cooperaçấo" dos documentos oficiais, mas também a possibilidade de compreender, por meio 
do referencial teórico apresentado, características do conteúdo das políticas que abordam a regionalização e que condicionam sua implementação, além de discutir a ação coletiva enquanto comportamento social.

Assim, os resultados foram distribuídos em duas seções: a primeira, que pretende discutir a ação coletiva e a cooperação enquanto elementos que alicerçam a política de regionalização, bem como aspectos que se apresentam como barreiras à sua implementação; e a segunda busca abordar os conceitos da ação coletiva e da cooperaçáo por meio da perspectiva das ciências sociais enquanto comportamento coletivo.

Quadro 1. Aspectos relacionados à açấo coletiva e cooperação em documentos oficiais que tratam sobre o processo de regionalização no Brasil, 1988 - 2018

\begin{tabular}{|c|c|c|c|}
\hline $\mathrm{N}$ & Instrumento & Conteúdo da Política & $\begin{array}{l}\text { Aspectos relacionados à ação coletiva/ } \\
\text { cooperaçáo }\end{array}$ \\
\hline 01 & $\begin{array}{l}\text { Constituição } \\
\text { Federal }\end{array}$ & $\begin{array}{l}\text { Constituição da } \\
\text { República Federativa } \\
\text { do Brasil de } 1988\end{array}$ & $\begin{array}{l}\text { Descreve que a organizaçáo político- } \\
\text { administrativa do Brasil compreende a União, } \\
\text { os estados, o Distrito Federal e os municípios, } \\
\text { todos autônomos. Determina que as açóes e } \\
\text { serviços públicos de saúde integram uma rede } \\
\text { regionalizada e hierarquizada constituindo um } \\
\text { sistema único, e que União e estados devem } \\
\text { prestar cooperação técnica e financeira aos } \\
\text { municípios para a implementação do SUS. }\end{array}$ \\
\hline 02 & $\begin{array}{l}\text { Lei } n^{\circ} 8.080 \text {, de } \\
19 \text { de setembro } \\
\text { de } 1990\end{array}$ & Lei Orgânica da Saúde & $\begin{array}{l}\text { Considera a regionalização como princípio e } \\
\text { eixo orientador do SUS. O termo "cooperação" } \\
\text { designa relação técnica de colaboração entre as } \\
\text { instituiçôes de ensino e os serviços de saúde, e } \\
\text { também a atuação da União com os demais entes } \\
\text { federados. Orienta a coordenação federativa } \\
\text { entre os entes (com ações complementares e } \\
\text { supletivas), obedecendo à hierarquizaçáo e níveis } \\
\text { de complexidade do sistema (CF 1988, inciso } \\
\text { VII). Destaca o apoio técnico e financeiro da } \\
\text { União aos demais entes federados. }\end{array}$ \\
\hline
\end{tabular}

continua... 


\begin{tabular}{|c|c|c|c|}
\hline $\mathrm{N}$ & Instrumento & Conteúdo da Política & $\begin{array}{c}\text { Aspectos relacionados à ação coletiva/ } \\
\text { cooperaçáo }\end{array}$ \\
\hline 03 & $\begin{array}{l}\text { Portaria GM/ } \\
\text { MS no 234, de } \\
7 \text { de fevereiro } \\
\text { de } 1992\end{array}$ & $\begin{array}{l}\text { Norma Operacional } \\
\text { Básica } 01 / 92\end{array}$ & $\begin{array}{l}\text { Enfatiza a municipalização dos serviços de saúde } \\
\text { (com estímulos financeiros), a hierarquização } \\
\text { e a direção única em cada esfera de governo. } \\
\text { Determina que estados e União possam executar } \\
\text { serviços de maneira supletiva, quando o ente } \\
\text { hierárquico não o executa. Estimula a cogestão } \\
\text { e cooperação técnica entre entes de maior } \\
\text { capacidade gestora. Determina ao ente estadual } \\
\text { a responsabilidade pela coordenação de serviços } \\
\text { ambulatoriais nos municípios. }\end{array}$ \\
\hline 04 & $\begin{array}{l}\text { Portaria GM/ } \\
\text { MS no } 545 \text {, de } \\
20 \text { de maio de } \\
1993\end{array}$ & $\begin{array}{l}\text { Norma Operacional } \\
\text { Básica } 01 / 93\end{array}$ & $\begin{array}{l}\text { Estimula a relação interfederativa e } \\
\text { a cooperação. Entende o processo de } \\
\text { regionalização como articulação e mobilizaçáo } \\
\text { municipal. Cria as comissóes intergestores } \\
\text { tripartite (CIT) e bipartite (CIB), além de } \\
\text { reforçar o papel dos conselhos enquanto espaço } \\
\text { de negociação política. Amplia os incentivos } \\
\text { à descentralizaçáo dos serviços com condiçóes } \\
\text { de gestáo, para Estados (Fator de Apoio aos } \\
\text { Estados - FAE) e municípios (Fator de Apoio aos } \\
\text { Municípios - FAM). }\end{array}$ \\
\hline 05 & $\begin{array}{l}\text { Portaria } \\
\text { GM/MS no } \\
2.203 \text {, de } 3 \text { de } \\
\text { novembro de } \\
1996\end{array}$ & $\begin{array}{l}\text { Norma Operacional } \\
\text { Básica 01/96 }\end{array}$ & $\begin{array}{l}\text { Sua principal finalidade é consolidar a função } \\
\text { e coordenação gestora municipal. Define } \\
\text { responsabilidades entre os entes federados, } \\
\text { destacando a "cooperação" técnica e financeira } \\
\text { do ente estadual e federal. Apresenta } \\
\text { preocupação com a formação atomizada } \\
\text { e desordenada entre os entes municipais e } \\
\text { reforça o ente estadual como o responsável à } \\
\text { harmonização, integração e modernização dos } \\
\text { sistemas municipais com equidade (admitindo } \\
\text { o princípio da discriminação positiva, para } \\
\text { o exercício do papel redistributivo). Induz a } \\
\text { conformaçáo de um novo modelo de gestão, com } \\
\text { enfase à direçáo única, e na construção de redes } \\
\text { regionalizadas e hierarquizadas de serviços. }\end{array}$ \\
\hline
\end{tabular}

continua... 


\begin{tabular}{|c|c|c|c|}
\hline $\mathrm{N}$ & Instrumento & Conteúdo da Política & $\begin{array}{c}\text { Aspectos relacionados à ação coletiva/ } \\
\text { cooperaçáo }\end{array}$ \\
\hline 06 & $\begin{array}{l}\text { Portaria GM/ } \\
\text { MS no } 95, \text { de } \\
26 \text { de janeiro de } \\
2001\end{array}$ & $\begin{array}{l}\text { Norma Operacional } \\
\text { da Assistência à Saúde } \\
2001\end{array}$ & $\begin{array}{l}\text { Considera os avanços e experiências exitosas } \\
\text { produzidas com os consórcios intermunicipais } \\
\text { de saúde, bem como, evidencia os obstáculos } \\
\text { e problemas decorrentes do amadurecimento } \\
\text { do processo de descentralização. Critica a } \\
\text { autonomia dos entes e a ausência de vínculos } \\
\text { hierárquicos do federalismo brasileiro. Aponta } \\
\text { que a regionalização pode superar os problemas } \\
\text { enfrentados, e destaca a necessidade de definição } \\
\text { de território, planejamento, e capacidade técnica } \\
\text { administrativa. Institui o PDR (Plano Diretor } \\
\text { de Regionalização), com ele o conceito de } \\
\text { Regiáo de Saúde e microrregióes, e ainda a PPI } \\
\text { (Programação Pactuada Integrada). Preza pela } \\
\text { solidariedade do município sob gestão plena } \\
\text { do sistema aos demais municípios. Busca pela } \\
\text { regionalização com o apoio dos Estados aos } \\
\text { municípios, para referências de MAC (média e } \\
\text { alta complexidade) e à construçáo da PPI. }\end{array}$ \\
\hline 07 & $\begin{array}{l}\text { Portaria GM/ } \\
\text { MS no } 373 \text {, de } \\
27 \text { de fevereiro } \\
\text { de } 2002\end{array}$ & $\begin{array}{l}\text { Norma Operacional } \\
\text { da Assistência à Saúde } \\
2002\end{array}$ & $\begin{array}{l}\text { Reforça as açōes propostas pela NOAS 01/2001. } \\
\text { Observa-se que as açóes têm caráter normativo, } \\
\text { com ausência de medidas que estimulem a } \\
\text { cooperação. Aborda que as açóes de MAC } \\
\text { devem ser organizadas de forma solidária entre } \\
\text { os entes Federal e estadual aos municípios. } \\
\text { Institui para municípios sob gestão plena } \\
\text { do sistema o "Termo de Compromisso para } \\
\text { a Garantia de Acesso", visando garantia do } \\
\text { atendimento à população referenciada residente } \\
\text { nos municípios de uma mesma região. }\end{array}$ \\
\hline
\end{tabular}

continua... 


\begin{tabular}{|c|c|c|c|}
\hline $\mathrm{N}$ & Instrumento & Conteúdo da Política & $\begin{array}{l}\text { Aspectos relacionados à ação coletiva/ } \\
\text { cooperaçáo }\end{array}$ \\
\hline 08 & $\begin{array}{l}\text { Portaria GM/ } \\
\text { MS no 399, de } \\
22 \text { de fevereiro } \\
\text { de } 2006\end{array}$ & Pacto pela Saúde & $\begin{array}{l}\text { Amplia a concepção de regionalização e reforça } \\
\text { os instrumentos de planejamento regional: PDR } \\
\text { (Plano de Desenvolvimento Regional), PPI e } \\
\text { PDI (Plano Diretor de Investimento). Menciona } \\
\text { que as regióes de saúde devem favorecer a ação } \\
\text { cooperativa e solidária entre os gestores, e } \\
\text { fortalecer o controle social. Para a construção } \\
\text { de redes deve haver pactuaçáo entre os atores } \\
\text { envolvidos. Institui o Colegiado Gestor Regional } \\
\text { (CGR) e apoio de câmaras técnicas. Atribui ao } \\
\text { ente estadual a coordenação das redes de atenção } \\
\text { à saúde. Define que os entes federados devem } \\
\text { contribuir para o fortalecimento do processo } \\
\text { de regionalização solidária e cooperativa para o } \\
\text { alcance da integralidade. }\end{array}$ \\
\hline 09 & $\begin{array}{l}\text { Portaria GM/ } \\
\text { MS nª 699, de } \\
30 \text { de março de } \\
2006\end{array}$ & $\begin{array}{l}\text { Regulamenta as } \\
\text { diretrizes operacionais } \\
\text { dos pactos pela vida e } \\
\text { de gestão. }\end{array}$ & $\begin{array}{l}\text { Aborda a diretriz da regionalização. Na pactuação } \\
\text { os municípios são estimulados a participar do } \\
\text { processo de regionalizaçáo solidária e cooperativa, } \\
\text { participar dos CGR, de projetos prioritários } \\
\text { da região descritos no PDR, e executar açóes } \\
\text { pactuadas descritas na PPI. Na pactuação } \\
\text { estadual destaca a coordenaçáo do processo de } \\
\text { regionalização pelo ente estadual e reforça a } \\
\text { regionalizaçáo cooperativa e solidária. Aborda } \\
\text { o apoio financeiro, tecnológico e de educação } \\
\text { permanente entre os entes, para construção } \\
\text { dos Termos de Compromissos de Gestáo, e a } \\
\text { cooperação entre os entes para referências de } \\
\text { MAC. Há indução de parcerias para construção } \\
\text { de protocolos clínicos e para assistência à saúde e } \\
\text { para a cogestão do processo de regulação. }\end{array}$ \\
\hline 10 & $\begin{array}{l}\text { Portaria } \\
\text { GM/MS no } \\
2.362 \text {, de } 6 \text { de } \\
\text { dezembro de } \\
2006\end{array}$ & $\begin{array}{l}\text { Torna público o termo } \\
\text { de compromisso de } \\
\text { gestáo federal. }\end{array}$ & $\begin{array}{l}\text { Reforça a regionalização solidária e cooperativa } \\
\text { como eixo prioritário, a partir da cooperaçáo } \\
\text { com recursos humanos, tecnológica e financeira } \\
\text { às regióes de saúde, especialmente às mais } \\
\text { vulneráveis. A coordenaçáo do processo de } \\
\text { regionalização no âmbito nacional. Estimula o } \\
\text { apoio financeiro e tecnológico para a educação } \\
\text { permanente. }\end{array}$ \\
\hline
\end{tabular}

continua... 


\begin{tabular}{|c|c|c|c|}
\hline $\mathrm{N}$ & Instrumento & Conteúdo da Política & $\begin{array}{l}\text { Aspectos relacionados à ação coletiva/ } \\
\text { cooperaçáo }\end{array}$ \\
\hline 11 & $\begin{array}{l}\text { Portaria GM/ } \\
\text { MS no 2.691, } \\
\text { de } 19 \text { de } \\
\text { outubro de } \\
2007\end{array}$ & $\begin{array}{l}\text { Regulamenta as } \\
\text { condiçôes para } \\
\text { transferência de } \\
\text { recursos financeiros } \\
\text { federais referentes } \\
\text { ao incentivo para } \\
\text { apoiar as açốes de } \\
\text { regionalização no SUS. }\end{array}$ & $\begin{array}{l}\text { Considera que os gestores devem promover } \\
\text { e apoiar a regionalização, disponibilizando } \\
\text { de forma cooperativa recursos humanos, } \\
\text { tecnológicos e financeiros necessários. } \\
\text { Regulamenta as condições de transferência } \\
\text { dos recursos financeiros federais para apoiar a } \\
\text { organização e o funcionamento dos CGR. }\end{array}$ \\
\hline 12 & $\begin{array}{l}\text { Portaria GM/ } \\
\text { MS no 4.279, } \\
\text { de } 30 \text { de } \\
\text { dezembro de } \\
2010\end{array}$ & $\begin{array}{l}\text { Estabelece diretrizes } \\
\text { para a organizaçáo } \\
\text { da Rede de Atenção } \\
\text { à Saúde (RAS) no } \\
\text { âmbito do SUS }\end{array}$ & $\begin{array}{l}\text { Entre as diretrizes, propõe que os CGR sejam } \\
\text { espaços permanentes de pactuação, cogestão } \\
\text { solidária e participativa, onde deve ser } \\
\text { exercida a governança das redes. Afirma que a } \\
\text { governança das RAS implica o enfrentamento } \\
\text { de questôes políticas e estruturais do processo } \\
\text { de regionalização (como as relaçôes federativas, } \\
\text { relaçôes público-privadas, regulaçáo, padrôes de } \\
\text { gestáo, entre outros). Orienta que a organizaçáo } \\
\text { do sistema em redes possibilita a construção de } \\
\text { vínculos de solidariedade e cooperação. }\end{array}$ \\
\hline 13 & $\begin{array}{l}\text { Decreto GM/ } \\
\text { MS no } 7.508 \text {, } \\
\text { de } 28 \text { de junho } \\
\text { de } 2011\end{array}$ & $\begin{array}{l}\text { Regulamenta a Lei no } \\
8.080 / 90, \text { para dispor } \\
\text { sobre a organizaçáo do } \\
\text { SUS, o planejamento } \\
\text { da saúde, a assistência } \\
\text { à saúde e a articulação } \\
\text { interfederativa, e dá } \\
\text { outras providências. }\end{array}$ & $\begin{array}{l}\text { Reforçam os conceitos de região, redes de } \\
\text { atenção, comissão intergestores, entre outros. } \\
\text { Institui o COAP (Contrato Organizativo da } \\
\text { Ação Pública de Saúde) para ser elaborado em } \\
\text { todas as regiōes de saúde do país, e estabelece } \\
\text { requisitos para sua organização. Não menciona } \\
\text { características para o processo de cooperação } \\
\text { no contrato, tão pouco, punição a sua não } \\
\text { elaboração. }\end{array}$ \\
\hline 14 & 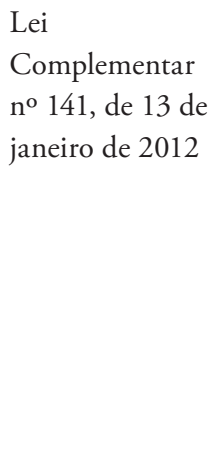 & $\begin{array}{l}\text { Regulamenta o } \$ \\
\text { 3o do art. } 198 \text { da } \\
\text { Constituiçáo Federal } \\
\text { para dispor sobre } \\
\text { os valores mínimos } \\
\text { a serem aplicados } \\
\text { anualmente pela União, } \\
\text { Estados, Distrito } \\
\text { Federal e Municípios } \\
\text { em açóes e serviços } \\
\text { públicos de saúde. }\end{array}$ & $\begin{array}{l}\text { Destaca que o processo de planejamento e } \\
\text { orçamento será ascendente e deverá partir } \\
\text { das necessidades de saúde da população em } \\
\text { cada região. Destaca a cooperaçấo técnica e } \\
\text { financeira da Uniáo, ao apoiar outros entes na } \\
\text { implementação de processos de educaçấo da } \\
\text { saúde, e na entrega de bens e valores. }\end{array}$ \\
\hline
\end{tabular}




\begin{tabular}{|c|c|c|c|}
\hline $\mathrm{N}$ & Instrumento & Conteúdo da Política & $\begin{array}{c}\text { Aspectos relacionados à ação coletiva/ } \\
\text { cooperaçáo }\end{array}$ \\
\hline 15 & 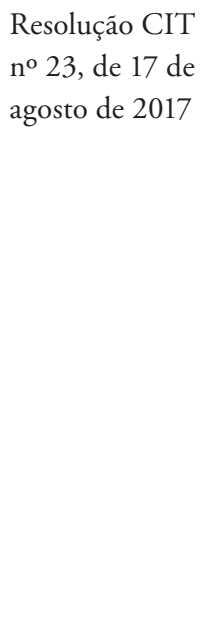 & $\begin{array}{l}\text { Estabelece diretrizes } \\
\text { para os processos } \\
\text { de regionalização, } \\
\text { planejamento regional } \\
\text { integrado, elaborado } \\
\text { de forma ascendente, } \\
\text { e governança das redes } \\
\text { de atenção à saúde no } \\
\text { âmbito do SUS. }\end{array}$ & $\begin{array}{l}\text { Estabelece diretriz para o processo de } \\
\text { regionalizaçâo, como medida alternativa a } \\
\text { não implantaçâo do COAP nas regiôes de } \\
\text { saúde. Enfatiza o processo de governança da } \\
\text { CIB, o planejamento ascendente e a alocação } \\
\text { de recursos de capital e custeio respeitando a } \\
\text { regionalização e a organizaçáo das RAS pelas } \\
\text { três esferas de gestão. Estabelece compromisso } \\
\text { dos três entes federados para implantação de } \\
\text { modelos de atenção à saúde que atenda às } \\
\text { políticas pactuadas e às necessidades de saúde } \\
\text { da população brasileira. Além de parâmetros } \\
\text { nacionais e regionalizados para orientar o } \\
\text { planejamento e a programação das ações e } \\
\text { serviços de saúde nas regiōes de saúde. }\end{array}$ \\
\hline 16 & $\begin{array}{l}\text { Resoluçáo CIT } \\
\text { no 37, de } 22 \text { de } \\
\text { março de } 2018\end{array}$ & $\begin{array}{l}\text { Dispóe sobre } \\
\text { o processo de } \\
\text { planejamento } \\
\text { regional integrado } \\
\text { e a organização de } \\
\text { macrorregiōes de } \\
\text { saúde. }\end{array}$ & $\begin{array}{l}\text { Institui o PRI (Planejamento Regional } \\
\text { Integrado), com intuito de compreender } \\
\text { necessidades do espaço regional ampliado } \\
\text { (ou macrorregião de saúde) para a construçáo } \\
\text { do Plano Regional, o qual será referência ao } \\
\text { financiamento das açóes e serviços públicos de } \\
\text { saúde (ASPS). }\end{array}$ \\
\hline
\end{tabular}

Fonte: os autores

\section{A ação coletiva e a cooperaçáo enquanto elementos das políticas de regionalização}

A ação coletiva, enquanto elemento político do processo de regionalização, foi abordada de forma mais explícita, com as Normas Operacionais de Assistência à Saúde (NOAS 01/2001 e 01/2002), como forma de garantir o acesso às açóes e serviços de saúde, em todos os níveis de atenção pelos cidadãos, entre os municípios. Entretanto, as NOAS não conseguiram alterar significativamente os serviços de saúde para a lógica regional, como as Normas Operacionais Básicas (NOB) fizeram no processo de municipalização durante a primeira década de implantação do SUS. Entre as razóes para tal, destaca-se que o federalismo no Brasil dotou o ente municipal de determinada autonomia e poder para a condução de políticas públicas, que em certa medida vivem o receio de transferi-los a outro ente. 
Além das NOAS, outras normativas ao processo de regionalização também podem ser destacadas, como a iniciativa do Pacto pela Saúde em estabelecer o eixo de regionalização no "Termo de Compromisso de Gestão (TCG)" - pactuando critérios essenciais ao desenvolvimento da política; a oportunidade de construçáo do Contrato Organizativo da Ação Pública (COAP) de saúde - pulverizado devido à necessidade de demonstração de recursos financeiros pelos entes contratantes, e não viabilizado em território nacional (OUVERNEY; RIBEIRO; MOREIRA, 2017); e as últimas resoluçôes da Comissão Intergestores Tripartite (CIT) que instituem o Planejamento Regional Integrado (PRI), estabelecem diretrizes ao processo de regionalização ascendente e reforçam os Colegiados Intergestores Regionais (CIR) como arena de negociação política e institucional das regiōes de saúde.

Quanto ao significado da ação coletiva e da cooperação nos documentos oficiais, observa-se que, dentre as normas selecionadas, muitas vezes esses termos são substituídos por outros vocábulos, como "solidariedade", no sentido de solidário, apoio (técnico, financeiro e científico), parceria e "cogestão".

A solidariedade é um princípio do sistema de saúde baseado na colaboração, apoio e parceria entre entes federados, na perspectiva da saúde como bem público e, portanto, responsabilidade de qualquer gestor. $\mathrm{Na}$ esfera jurídica, impóe as mesmas responsabilidades em relação ao direito à saúde a todos os entes federados, não importando seu tamanho e/ou renda (SANTOS, 2011). A cogestáo se refere aos esforços permanentes, políticos e técnicos, para o planejamento, articulação e pactuação das ações e estratégias dos serviços regionais, materializado por meio dos colegiados de gestão regional (CGR) - arranjos institucionais que permitem desenvolver de forma solidária e cooperativa tais funçôes (BRASIL, 2006a). A ação coletiva e a cooperação tendem a favorecer a maioria dos municípios integrantes de uma região e também o ente estadual responsável pelo território; no entanto, ela não ocorre de forma espontânea em um grupo e/ou colegiado. Sua manifestação dependerá da construção de arranjos institucionais, coordenação, e mecanismos de coerção (MENICUCCI; MARQUES, 2016).

Percebe-se que a lógica da ação solidária e cooperativa é intrínseca ao próprio desenvolvimento do SUS. No entanto, as características do federalismo centrífugo brasileiro, ao formar entes autônomos, mas não independentes, fomentou o surgimento de características contrárias à coletividade, especialmente com o processo de descentralização ou municipalização autárquica e desordenada como 
conceituam alguns autores (PESTANA; MENDES, 2004). Assim, se a ação coletiva e a cooperação estão diretamente vinculadas à relação federativa, e se esta se expressa por meio da regionalização, um fator importante a ser mencionado é que na organização político-administrativa da república federativa do Brasil a região de saúde não é contemplada (BRASIL, 1988).

Esse fato nos remete à condição de coordenação, já que este é um aspecto destacado para o desenvolvimento da ação coletiva e cooperação nos instrumentos jurídicos levantados. Para Abrucio (2005), a coordenação deve antecipar o processo de cooperação, ao considerar que o federalismo é intrinsecamente conflitivo. $\mathrm{Ou}$ seja, para o autor, a coordenação federativa de uma política incentiva o equilíbrio entre a cooperação e a competição existente entre os entes federados.

Nas normativas analisadas neste manuscrito, a responsabilidade de coordenação e apoio ao processo de regionalização, é majoritariamente do ente estadual, apesar das responsabilidades inequívocas dos municípios, DF e União. Na década de 1990, o processo de descentralização dos serviços de saúde esvaziou o papel de coordenação e de competências técnicas, acumuladas por anos na esfera estadual (MACHADO, 2009), permanecendo este ente restrito às medidas supletivas e complementares de serviços aos municípios sem organização técnica para tal, e ainda, apresentando constrangimentos para a aplicação mínima de recursos próprios em saúde.

Quanto ao processo de regionalização, compreende-se, a partir dos instrumentos apresentados, que o sistema tem tentado, pelo menos em relação às normas orientadoras do processo de condução política, destacar a regionalização como eixo prioritário e necessário à manutenção do sistema de saúde. No entanto, embora os instrumentos normativos do processo de regionalização criem condiçôes e incentivos para a produção da ação coletiva e da cooperação entre municípios e estados, sua aplicação é condicionada por determinadas escolhas, trajetórias e rumos possibilitados pelas políticas elencadas.

Sob a lógica neoinstitucional histórica (PIERSON, 2004), escolhas prévias das políticas de saúde, como as de municipalização, reforçam as trajetórias políticas do sistema nacional de saúde no Brasil e contribuem para a compreensão da organização do sistema atual. Nesse universo, práticas de gestão individualizadas são permanentemente reforçadas (feedback positivo) quando normativas de regionalização não se institucionalizam nos serviços de saúde. Assim, concebem maior rigidez institucional às políticas anteriores, e diminuem as possibilidades de sua 
alteração. Ao mesmo tempo, formaçôes de grupos de interesse sobre o financiamento descentralizado alteram a arena política e decisória, e impóem empecilhos ao processo de cooperação. Entende-se, portanto, que a ação coletiva e a cooperação são temas abordados e discutidos nas normas que envolvem a regionalização dos serviços de saúde, mas sua materialização depende, segundo o referencial de Scott (1995), de vários aspectos relacionados à institucionalidade política.

$\mathrm{Na}$ análise de políticas, Scott (1995) considera que a institucionalidade de uma política dependerá da presença de três mecanismos institucionais: o regulatório, o normativo e o cognitivo. O primeiro voltado a recompensas e puniçóes ao desenvolvimento de determinada política; o segundo relacionado ao comportamento humano, quanto à prática política como obrigação social e/ou moral; e o terceiro direcionado às questôes culturais, de preferências, e de identificação social.

Constata-se, entre os documentos oficiais elencados, a prevalência de instrumentos jurídicos altamente normativos, voltados à organização e indução da política de regionalização, quando comparados ao caráter regulatório desses instrumentos, quanto à perspectiva de recompensa aos que cooperam e puniçóes aos que desertam. Considera-se também que, apesar de a ação coletiva e a cooperação nortearem o processo político nas normativas do SUS, esses conceitos expressam ideais filosóficos e ideológicos, e assim, apresentam-se insuficientes para a modificação deste cenário, uma vez que esses princípios correspondem um capital valioso, mas facilmente negociável frente às necessidades de resultados individuais (OPAS, 2011). Ainda assim, a legislação caminha com proposições políticas positivas, como as duas últimas resoluções da CIT, que sinalizam a construção de instrumentos de planejamento macrorregional vinculados ao financiamento das açóes e serviços públicos de saúde no território regional (BRASIL, 2018a).

\section{A ação coletiva e a cooperação enquanto comportamento social}

Como apresentado na seção anterior, a ação coletiva e a cooperação se expressam nos documentos oficiais por meio de outros vocábulos, especialmente na condição de "solidariedade" e "cogestão". E apesar de os instrumentos jurídicos não permitirem decretar um comportamento social, a ação coletiva, por meio da solidariedade entre os entes federados, é constantemente abordada nos documentos oficiais. Dessa forma, entende-se que o conceito de ação coletiva é complexo, permeado de fatores 
facilitadores e inibidores ao processo de cooperação, mas pelo qual é possível emergir contribuições para a compreensão das relaçôes federativas e da regionalização.

Nesse sentido, são destacados quatro autores que subsidiam reflexóes acerca da ação coletiva, sob enfoque das ciências sociais: o estadunidense Mancur Olson (19321988), que também é economista e trata dos interesses dos membros das organizações; o italiano Alberto Melucci (1943-2001), que aponta para uma nova configuração solidária no âmbito da ação coletiva, sob o prisma da Teoria dos Novos Movimentos Sociais (TNMS) no contexto da contemporaneidade; a autora brasileira Maria da Glória Marcondes Gohn, que analisa o cenário em que se originam os movimentos sociais (coletivo), sua caracterização e seu percurso histórico no Brasil; e o cientista político e professor estadunidense Robert David Putnam, que adota a solidariedade como um capital social baseado em práticas e em relaçóes de confiança.

O primeiro referencial, discutido por Olson (2015) sob uma ótica racional, aborda aspectos fundamentais para a participação dos indivíduos na ação coletiva, sendo estes: a motivação; a relação entre os benefícios obtidos individualmente e no coletivo; e a natureza e a importância desses benefícios; de forma que o interesse comum, de maneira isolada, embora seja uma condição, não é suficiente para levar os membros do grupo à cooperação, sendo preciso que seus benefícios, ao agir coletivamente, superem os custos individuais. Além disso, há assimetria nos níveis de interesse dos membros e podem surgir situaçóes de exploração ou de concorrência entre os participantes do grupo. Isso se deve ao seu porte e em razão da medida de seus benefícios em comparação aos demais, uma vez que os indivíduos sempre terão interesses envolvidos no processo de cooperação.

Nessa perspectiva, a normatização definida nos documentos oficiais produziu alguns efeitos indesejáveis, embora os textos dessas normativas estimulassem a cooperação solidária entre os mesmos. Isto ocorreu devido à categorização dos municípios, em níveis de responsabilidades de gestão e coordenação, decorrentes desses documentos. Os municípios-polo, ao assumirem a modalidade de gestão semiplena (NOB 93) ou plena do sistema (NOB 96) se tornaram, de fato, gestores do sistema de saúde, com o controle de todos os recursos financeiros, inclusive os de média e alta complexidade (MAC), recebidos por meio de transferência fundo a fundo, e destinados ao atendimento não só de seus munícipes, mas também para a referência da regiáo/macrorregiáo que compóem. Assim, ganharam autonomia para a tomada de decisão acerca da aplicação dos recursos, pactuação de metas 
junto aos prestadores de serviços e organização dos mecanismos de regulação. Ou seja, adquiriram maior controle sobre os recursos do sistema macrorregional, embora as comissões intergestores regionais permitam a pactuação e o debate entre os municípios. Desta forma, os municípios, especialmente os pequenos, ficaram subordinados aos municípios "plenos", ocasionando relações de conflito.

Observa-se também que diversos documentos contribuem com aspectos positivos, técnicos e processuais para a ação coletiva e regionalização. As NOAS e o Pacto de Gestão, por exemplo, carregam diversos aspectos conceituais do processo de regionalização, além de instituírem e reforçarem uma série de instrumentos (PDR, PPI, PDI) com vistas a melhorar a coordenação e a cogestão dos espaços regionais. Entretanto, por se tratar de documentos oficiais, são altamente normativos e textualmente técnicos. Assim, questiona-se como o sistema poderia estimular a mudança de atitude de gestores e a ressignificação da solidariedade entre os entes no atual cenário da regionalizaçáo? Particularmente, como convidar gestores e trabalhadores do SUS a repensarem a maneira como organizam a ação coletiva e solidária, de forma que essas características também sejam incorporadas nas práticas de planejamento e da gestão em saúde?

Demais autores que discutem referenciais, como capital social e ação coletiva, auxiliam neste aspecto. Putnam (1993) afirma que a ação em coletividade é derivada da contribuição do capital social individual de cada ator político ao coletivo, compreendendo o capital social como um bem público, expresso por características da organizaçáo social que incluem normas de reciprocidade, redes de solidariedade e confiança entre as pessoas. Dessa forma, açôes de capital social como confiança, normas e redes, tendem a ser autorreforçadoras e cumulativas, e podem capacitar as pessoas a agirem coletivamente (PUTNAM, 1993).

Melucci (1989) aponta que a agregaçáo social se torna um fenômeno permanente, e embora tenha variaçóes em suas formas, trata-se de um componente estável e irreversível da contemporaneidade. Além disso, o autor ressalta que os atores envolvidos na ação coletiva não se motivam apenas por questôes econômicas (custos e vantagens) ou por questôes políticas, mas também buscam outros bens imensuráveis, como autorrealização, solidariedade e identidade, de forma que, orientados para a ação social, estes superam a luta pelo poder ou por bens de consumo.

Outro aspecto das políticas que tratam da regionalização e que deve ser destacado é a institucionalização dos CGR, por meio do Pacto pela Saúde. Esses espaços são 
caracterizados como ambientes propícios ao desenvolvimento de cogestão e de identidades coletivas, marcados por consensos e dissensos entre atores envolvidos, uma vez que a identidade coletiva, segundo Melluci (2001), não é algo dado ou uma essência, mas um produto de trocas, negociaçóes, decisóes e conflitos.

Contribuindo para esse entendimento, Gohn (2000) destaca que a ação coletiva não é apenas a soma de vontades individuais, mas requer um projeto coletivo. Neste sentido, a compreensão acerca da ação coletiva mostra que, ao passo que o processo de regionalização se consolida, mais chances os gestores de saúde de uma região têm de desenvolver um projeto coletivo. Tais iniciativas, uma vez motivadas pela solidariedade e autorrealização entre os agentes, serão bem-sucedidas ao ponto que a cooperação os leva ao alcance de objetivos comuns.

Gohn (2000) caracteriza um movimento social como a ação dos homens na história, que pressupóe o fazer por meio de um conjunto de práticas sociais. A autora ressalta que a dimensão política é um fator central no agir social constitutivo dos movimentos e que há alguns pressupostos para que a ação coletiva seja considerada um movimento social, tal como a necessidade que exista algo para além dos interesses comuns, formando-se assim um coletivo social, uma identidade coletiva, que supóe uma demanda comum (GOHN, 2000). Com isso, a caracterização de movimento social pode ser um conceito que se assemelha aos ideários da relação federativa.

Considerando os documentos oficiais que abordam a açâo coletiva, Melucci (1989) afirma que o fenômeno de cooperação é desenvolvido por meio da interação de três aspectos de uma política: seus objetivos, recursos e obstáculos, os quais estarão inseridos em um sistema de oportunidades e coerçôes. Esses elementos, segundo Melucci (1989), deveriam nortear estruturas normativas e documentos oficiais de políticas, tais como as que direcionam o processo de regionalização no campo da saúde pública.

Diante do exposto acerca dos conceitos e nuances da ação coletiva e sua conceituação diante dos interesses individuais ou coletivos, e tendo em vista a abordagem teórica dos novos movimentos sociais, é possível perceber que esse tema impulsiona as reflexôes acerca das relaçôes federativas, da cooperação e da regionalização. Com isso, a ação coletiva apresenta-se como um fenômeno essencial a ser posicionado no âmbito da regionalizaçáo, sobretudo diante da proposta de identificação, análise e socialização de estratégias de cooperação entre os entes federativos. Além disso, a ação coletiva configura-se como eixo motivador para o 
processo decisório e de mudanças, o qual se refere à construção de políticas públicas, cabendo abordá-la sob o enfoque dos valores da solidariedade e da cooperaçáo.

\section{Consideraçôes finais}

Os documentos oficiais que tratam da regionalização dos serviços de saúde orientam e influenciam processos decisórios e abordam, por vezes, a conduta cooperativa e a ação coletiva, utilizando-se de outros vocábulos, como solidariedade, apoio, parceria e cogestão. Compreende-se também que a ação coletiva e a cooperação se expressam enquanto elemento de políticas federativas e em certa medida enquanto comportamento social.

$\mathrm{Na}$ atualidade, o sistema de saúde brasileiro vem passando por profundas mudanças relacionadas ao financiamento de ações, e sua manutenção depende, em certo grau, de políticas voltadas à cooperação entre entes de uma mesma região de saúde. $\mathrm{O}$ assunto permanece na agenda de políticas de saúde, apesar de não constar como eixo de prioridade de pesquisa no Ministério da Saúde. Nos últimos instrumentos jurídicos relacionados ao tema, o planejamento integrado das necessidades macrorregionais e o custeio de açóes baseados nesses instrumentos sinalizam condutas de cooperação entre os entes federados.

Esse processo deve ser capitaneado e coordenado pelo ente estadual, ao reforçar potencialidades municipais e possibilitar a formação de grupos de articulação e decisão gestora macro e microrregional. As políticas indutoras do processo de regionalização deverão lançar mão de mecanismos regulatórios, formados por recompensas e coerçóes aos atores políticos envolvidos neste processo, para que amplie as chances de institucionalidade.

Para a cooperação entre indivíduos de um mesmo grupo, muitos desafios devem ser transpostos, entre eles, equilíbrio entre os interesses coletivos e individuais, organização do processo de ação coletiva e a construção de identidades sociais entre gestores com vistas à cogestão.

Aprofundar-se nos referenciais dos movimentos sociais também permite compreender melhor o conceito de ação coletiva, em especial, quando ressalta o sentido de solidariedade e identidade, aos quais acrescentam ainda outros fatores, como a ação, a ideologia, a cultura e as lutas cotidianas. Além disso, relaçôes de reciprocidade, solidariedade e confiança devem ser estimuladas na gestão dos 
serviços de saúde, a fim de aumentar o capital social de seus integrantes e possibilitar a cooperação e a ação em coletividade. ${ }^{1}$

\section{Referências}

ABRUCIO, F. L. A coordenação federativa no Brasil: a experiência do período FHC e os desafios do governo Lula. Revista de Sociologia e Política, Curitiba, n. 24, p. 41-67, 2005.

BARDIN, L. Análise de conteúdo. Lisboa: Edições 70, 1977.

BRASIL. Ministério da Saúde. Agenda de prioridades de pesquisa do Ministério da Saúde. Brasília, DF: Ministério da Saúde, 2018b.

. Ministério da Saúde. Comissão Intergestores Tripartite. Resolução CIT no 23, de 17 de agosto de 2017. Estabelece diretrizes para os processos de regionalização, planejamento regional integrado, elaborado de forma ascendente, e governança das redes de atenção à saúde no âmbito do SUS. Brasília, DF, 2017.

. Ministério da Saúde. Comissão Intergestores Tripartite. Resolução CIT no 37, de 22 de março de 2018. Dispóe sobre o processo de planejamento regional integrado e a organização de macrorregiōes de saúde. Brasília, DF, 2018a.

. Ministério da Saúde. Decreto no 7.508, de 28 de junho de 2011. Regulamenta a Lei no 8.080, de 19 de setembro de 1990, para dispor sobre a organizaçáo do Sistema Único de Saúde - SUS, o planejamento da saúde, a assistência à saúde e a articulação interfederativa, e dá outras providências. Diário Oficial da União, Brasília, DF, 29 jun. 2011.

. Ministério da Saúde. Portaria GM/MS no 2.691, de 19 de outubro de 2007. Regulamenta as condiçóes para transferência de recursos financeiros federais referentes ao incentivo para apoiar as açôes de regionalização no sistema único de saúde. Brasília, DF: Ministério da Saúde, 2007.

. Ministério da Saúde. Portaria GM/MS no 2203, de 5 de novembro de 1996. Norma Operacional Básica 01/96. Atos Normativos. Brasília, DF: Ministério da Saúde, 1996.

Ministério da Saúde. Portaria GM/MS no 234, de 7 de fevereiro de 1992. Norma Operacional Básica 01/92. Atos Normativos. Brasília, DF: Ministério da Saúde, 1992.

Ministério da Saúde. Portaria GM/MS no 373, de 27 de fevereiro de 2002. Norma Operacional de Assistência à Saúde NOAS-SUS 01/02. Brasília, DF: Ministério da Saúde, 2002. . Ministério da Saúde. Portaria GM/MS no 399, de 22 de fevereiro de 2006. Divulga o Pacto pela Saúde. Brasília, DF: Ministério da Saúde, 2006b.

. Ministério da Saúde. Portaria GM/MS no 4.279, de 30 de dezembro de 2010. Estabelece diretrizes para a organização da rede de atenção à saúde no âmbito do sistema único de saúde (SUS). Brasília, 2010. 
Ministério da Saúde. Portaria GM/MS no 545, de 20 de maio de 1993. Norma Operacional Básica 01/93. Atos Normativos. Brasília, DF: Ministério da Saúde, 1993.

Ministério da Saúde. Portaria GM/MS no 95, de 26 de janeiro de 2001. Norma Operacional de Assistência à Saúde NOAS-SUS 01/01. Brasília, DF: Ministério da Saúde, 2001.

- Ministério da Saúde. Regionalização solidária e cooperativa: orientaçôes para implementação no SUS. Série Pactos pela Saúde. Brasília, v. 3, 2006a.

- Presidência da República. Lei Complementar no 141, de 13 de janeiro de 2012. Regulamenta o parágrafo $3^{\circ}$ do artigo 198 da Constituição Federal, revoga os dispositivos das Leis no 8.080 de 1990 e 8.689 de 1993 e dá outras providências. Brasília, DF, 2012.

. Presidência da República. Lei no 8.080, de 19 de setembro de 1990. Dispóe sobre as condiçôes para a promoção, proteção e recuperação da saúde, a organização e o funcionamento dos serviços correspondentes e dá outras providências. Brasília, 1990.

. Ministério da Saúde. Portaria GM/MS no 2.362, de 6 de dezembro de 2006. Torna público o termo de compromisso de gestão federal. Brasília, DF: Ministério da Saúde, 2006c.

. Ministério da Saúde. Portaria GM/MS no 699, de 30 de março de 2006. Regulamenta as diretrizes operacionais dos pactos pela vida e de gestão. Brasília, DF: Ministério da Saúde, 2006d. BRASIL. Senado Federal. Constituição da República Federativa do Brasil. Brasília, DF: Senado Federal: Centro Gráfico, 1988.

CARvalHO, B. G. et al. Programa de qualificação e apoio às equipes municipais de gestão e planejamento. Oficina 1. Sergestor e regionalização, 2019. Disponível em: <https://beeacdd1-f56e4c04-8f11-d8cebce247f8.filesusr.com/ugd/7e69a9_a78fb665055d464481af4447f09da5d9. pdf>. Acessado em: 01 jun. 2020.

GOHN, M. G. M. 500 anos de lutas sociais no Brasil: movimentos sociais, ONGs e terceiro setor. Rev. Mediaçôes, Londrina, v. 5, n. 1, p. 11-40, 2000.

GOHN, M. G. M. Teoria dos movimentos sociais: paradigmas clássicos e contemporâneos. São Paulo: Edições Loyola, 1977.

LIMA, L. D. Condicionantes da regionalização da saúde no Brasil: desafios e recomendaçóes para o planejamento e a gestão territorial do SUS no horizonte dos próximos 20 anos. Textos para discussão. Rio de Janeiro: Fiocruz, 2015.

MACHADO, J. A. Pacto de gestão na saúde: até onde esperar uma "regionalização solidária e cooperativa"? Revista Brasileira de Ciências Sociais, São Paulo, v. 24, n. 71, p. 105-119, 2009.

MELUCCI, A. Um objetivo para os movimentos sociais. CEDEC, Lua Nova. São Paulo, n. 17, p. 49-66, 1989.

MELUCCI, A. A invenção do presente. Rio de Janeiro: Vozes, 2001. 
MENICUCCI, T.; MARQUES, A.M.F. Coordenação e cooperação na implementação de políticas públicas: o caso da saúde. DADOS - Revista de Ciências Sociais, Rio de Janeiro, v. 59, n.3, p. 823-865, 2016.

MINAYO, M. C. S. O desafio do conhecimento: pesquisa qualitativa em saúde. 12.ed., São Paulo: Hucitec/Abrasco, 2010

OLSON, M. A lógica da ação coletiva: os benefícios públicos e uma teoria dos grupos sociais. São Paulo: EdUSP, 2015.

ORGANIZAÇÃO PAN-AMERICANA DA SAÚDE. Redes e regionalização em saúde no Brasil e na Itália: liçôes aprendidas e contribuiçôes para o debate. Brasília: OPAS, 2011.

OUVERNEY, A. M.; RIBEIRO, J. M.; MOREIRA, M. R. O COAP e a Regionalização do SUS: os diversos padrôes de implementaçấo nos estados brasileiros. Ciência e Saúde Coletiva, Rio de Janeiro, v. 22, n. 4, p. 1.193-1.207, 2017.

PESTANA, M.; MENDES, E. V. Pacto de gestão: da municipalização autárquica à regionalização cooperativa. Belo Horizonte, 2004.

PIERSON, P. Politics in time: history, institutions, and social analysis. Princeton: Princeton University Press; 2004.

PUTNAM, R. D. Making democracy work: civic traditions in modern Italy. Princeton: Princeton University Press, 1993.

SANTOS, L. O princípio da solidariedade no SUS. Blog Direito Sanitário: Saúde e Cidadania, 2011. Disponível em: <http://blogs.bvsalud.org/ds/2011/09/30/o-principio-da-solidariedadeno-sus/>. Acesso em: 15 fev. 2019.

SCOTT, R. W. Institutions and Organizations. Thousand Oaks, CA: Sage. 1995.

VIANA, A. L. D.; LIMA, L. D. Regionalização e relaçôes federativas na política de saúde do Brasil. Rio de Janeiro: Contra Capa, 2011.

\section{Nota}

${ }^{1}$ J. F. M. da Silva e B. G. Carvalho delimitaram o recorte da pesquisa e contribuíram na concepção, redação e aprovação da versão final do artigo. S. K. A. V. Andrade participou da redação, revisão e aprovou a versão final do artigo. C. M. Domingos participou na delimitação do recorte da pesquisa e em sua concepção. 


\section{Abstract}

\section{Collective action and cooperation in the Unified Health System}

Although the principle of regionalization of health services is contained in official documents and guides the current organization of the Unified Health System, this process depends to a certain extent on collective action and cooperation between federated entities. Collective action and cooperation are considered elements of federal policies and social behavior. In this perspective, we sought to analyze how collective action and cooperation are addressed in the official documents of regulation and organization of health policies that deal with regionalization. It is a documentary analysis of 16 official norms, published between 1988 and 2018, and discussion of the theme, supported mainly by the collective and political institutional frameworks. For the analysis of official documents, the technique of content analysis was used. The results show that collective action and cooperation are addressed in official documents, especially by the words "solidarity" and "co-management", and that regionalization policies have a highly normative character. Its implementation will depend on coordination, coercion, and reward mechanisms, as well as aspects related to the management of services, such as balance between collective and individual interests, and the construction of social identities between managers with a view to comanagement.

> Keywords: Regional Health Planning, Collective Action, Cooperation, Decentralization, Public Policy. 